\title{
Cryoablation during left ventricular assist device implantation reduces postoperative ventricular tachyarrhythmias
}

\author{
Daniel P. Mulloy, MD, ${ }^{a}$ Castigliano M. Bhamidipati, DO, MSc, ${ }^{a}$ Matthew L. Stone, MD, ${ }^{a}$ \\ Gorav Ailawadi, MD, ${ }^{\mathrm{a}}$ James D. Bergin, MD, ${ }^{\mathrm{b}}$ Srijoy Mahapatra, MD, ${ }^{\mathrm{b}}$ and John A. Kern, MD ${ }^{\mathrm{a}}$
}

Background: The number of patients undergoing implantation of a HeartMate II left ventricular assist device (LVAD; Thoratec Corporation, Pleasanton, Calif) is rising. Ventricular tachyarrhythmia (VA) after placement of the device is common, especially among patients with preoperative VA. We sought to determine whether intraoperative cryoablation in select patients reduces the incidence of postoperative VA.

Methods: From January 2009 through September 2010, 50 consecutive patients undergoing implantation of the HeartMate II LVAD were examined. Fourteen of these patients had recurrent preoperative VA. Of those patients with recurrent VA, half underwent intraoperative cryoablation (Cryo: $\mathrm{n}=7$ ) and half did not (NoCryo: $\mathrm{n}=7$ ). Intraoperatively, patients underwent localized epicardial and endocardial cryoablation via LVAD ventriculotomy. Cryothermal lesions were created to connect scar to fixed anatomic borders in the region of clinical VA. Demographics, risk factors, intraoperative features, and outcomes were analyzed to investigate the feasibility of cryoablation.

Results: Thirty-day mortality remained low $(\mathrm{n}=1,2 \%)$ among all LVAD recipients. There were no differences in risk factors between groups except that preoperative inotropes were less prevalent in Cryo patients $(P=.09)$. Compared with NoCryo, the Cryo group had significantly decreased postoperative resource use and complications $(P<.05)$. Recurrent postoperative VA did not develop in any of the Cryo patients $(P=.02)$.

Conclusions: Postoperative VA can be minimized by preoperative risk assessment and intraoperative treatment. Localized cryoablation in select patients offers promising early feasibility when performed during HeartMate II LVAD implantation. Further prospective analysis is required to investigate this novel approach. (J Thorac Cardiovasc Surg 2013;145:1207-13)

Mechanical left ventricular assist devices (LVADs) have become accepted as an important therapeutic modality for patients with end-stage heart failure. Ventricular tachyarrhythmias (VAs) are common in patients supported with LVADs, with reported incidences ranging from $22 \%$ to $52 \% .^{1-3}$ As LVAD technology, operative technique, and postoperative care improve, the duration of LVAD support is increasing in both bridge-to-transplant and destination therapy groups. Although tolerance of VAs in the LVAD population is improved compared with that of unsupported patients, ${ }^{4}$ VAs still contribute to mortality, hemodynamic instability, and prolonged hospitalization in LVAD recipients. ${ }^{1}$ A standardized strategy for prevention and care of VAs is needed to maximize outcomes of patients supported by LVADs.

\footnotetext{
From the Division of Thoracic and Cardiovascular Surgery, ${ }^{\mathrm{a}}$ Department of Surgery, and the Division of Cardiovascular Medicine, ${ }^{\mathrm{b}}$ Department of Medicine, University of Virginia Health System, Charlottesville, Va.

Disclosures: Authors have nothing to disclose with regard to commercial support. Received for publication Jan 18, 2012; revisions received March 13, 2012; accepted for publication March 22, 2012; available ahead of print April 23, 2012.

Address for reprints: John A. Kern, MD, University of Virginia Health Science Center, Department of Cardiothoracic Surgery, Box 310-88, Charlottesville, VA 22908 (E-mail: JAK3R@virginia.edu)

$0022-5223 / \$ 36.00$

Copyright (C) 2013 by The American Association for Thoracic Surgery doi:10.1016/j.jtcvs.2012.03.061
}

Given the high rate of postoperative VAs in LVADsupported patients both at our institution and in the literature, we sought to develop a treatment strategy with the goal of limiting clinically significant postoperative VAs in LVAD recipients. A high failure rate was observed with attempts at catheter-based postoperative ablations; therefore, an intraoperative approach using cryoablation during LVAD placement was chosen. Patient selection for initial use of this novel treatment strategy focused on those deemed to be at highest risk for postoperative VAs. Patients with more than 1 episode of preoperative VA were selected to undergo targeted intraoperative epicardial and endocardial cryoablation at the time of LVAD placement. Initial results observed in several patients ${ }^{5}$ prompted further use of this approach and this study was performed as an early feasibility analysis of our novel technique.

\section{METHODS \\ Patients \\ This study was approved by the human investigation committee of the University of Virginia Health System (HSR 15225). All LVAD operations at our institution were entered prospectively into The Society of Thoracic Surgeons (STS) National Database. We retrospectively reviewed all pa- tients at our institution undergoing placement of a HeartMate II LVAD (Thoratec Corporation, Pleasanton, Calif) from January 2009 to September 2010. Patient characteristics, demographics, risk factors, operative fea- tures, and postoperative outcomes were evaluated using a combination of}




$$
\begin{aligned}
& \text { Abbreviations and Acronyms } \\
& \text { Cryo = cryoablation group } \\
& \text { EP }=\text { electrophysiology } \\
& \text { ICU }=\text { intensive care unit } \\
& \text { LVAD }=\text { left ventricular assist device } \\
& \text { NoCryo }=\text { no cryoablation group } \\
& \text { STS }=\text { The Society of Thoracic Surgeons } \\
& \text { SVR }=\text { surgical ventricular reconstruction } \\
& \text { VA }=\text { ventricular tachyarrhythmia }
\end{aligned}
$$

STS data and data obtained by review of inpatient and outpatient hospital records. With the exception of VA-related data points, we used known STS database definitions to describe all preoperative and operative variables as well as postoperative outcomes. VA was defined as more than 30 seconds of documented ventricular tachycardia or ventricular fibrillation as seen on a rhythm strip, electrocardiographic tracing, or implantable cardiac defibrillator readout. "Recurrent" preoperative or postoperative VA was defined as greater than 1 episode of documented VA present at any point before or after the LVAD operation. Of the 50 consecutive patients, 14 were identified as having recurrent preoperative VAs. These 14 patients, with multiple episodes of documented VA before LVAD placement, were separated for subgroup analysis to determine the early feasibility of intraoperative cryoablation in LVAD recipients with recurrent preoperative VA. In February 2010, the first patient in our series underwent intraoperative cryoablation at the time of LVAD implantation. All subsequent patients with a history of recurrent preoperative VA also underwent intraoperative cryoablation. Therefore, of the 14 patients with a history of recurrent VA, the latter 7 underwent intraoperative cryoablation (Cryo); the initial 7 did not (NoCryo). Subgroup analysis comparing these 2 groups of 7 patients was performed.

\section{Operative Technique}

Before LVAD implantation, an effort was made to identify the anatomic location of arrhythmogenic substrate in those patients selected for intraoperative cryoablation. Patients stable enough for transport to the electrophysiology $(\mathrm{EP})$ laboratory $(\mathrm{n}=4)$ underwent preoperative EP substrate mapping. In those patients not stable enough for transport $(n=3)$, electrocardiograms capturing ventricular tachycardia were systematically analyzed by a heart failure cardiologist, electrophysiologist, and cardiac surgeon to identify the approximate origin of arrhythmogenesis. Standard HeartMate II LVADs were then placed in all patients. After complete median sternotomy, the preperitoneal pocket was created to accommodate the LVAD pump and partial cardiopulmonary bypass was initiated. In patients undergoing intraoperative ablation, epicardial cryoablation was then performed using an AtriCure device (AtriCure, Inc, Cincinnati, Ohio) with a liquid nitrogen-cooled Cryo1 probe (AtriCure; Figure 1). Each preidentified site of arrhythmogenic substrate was ablated at $-70^{\circ} \mathrm{C}$ for $2 \frac{1}{2}$ minutes. After epicardial ablation, full bypass was initiated, the aorta was crossclamped, and cardioplegic solution was administered. We opted to perform the endocardial ablation and LVAD placement on the arrested heart although these procedures can also be performed on the empty beating heart. The coring device was used to create a ventriculotomy for placement of the LVAD inflow cannula and the AtriCure device was again used with the Cryo1 probe for endocardial ablation via the previously performed ventriculotomy (Figure 1). For endocardial ablation in the arrested and nonperfused heart, we reduced cryoablation time to 2 minutes, again at $-70^{\circ} \mathrm{C}$. Appropriate loci for cryoablation were identified preoperatively after careful review of EP mapping studies and/or electrocardiograms by the heart failure cardiologist, electrophysiologist, and cardiac surgeon. To prevent development of subsequent reentry circuits, we took care to ablate the previously identified arrhythmogenic site in addition to creating a surrounding ablation tract extending from the arrhythmogenic substrate to fixed anatomic sites such as the mitral valve and/or apical LVAD inflow cannula. Given the subsequent LVAD ventricular support, maximal ventricular preservation is not as vital and cryoablation was used liberally, especially when treating left ventricular lesions. In cases in which multiple or larger areas of arrhythmogenesis were identified preoperatively, large sections of ventricle underwent epicardial and endocardial cryoablation. No intraoperative or routine postoperative EP mapping was performed. After completion of the endocardial ablation, circumferential stitches were placed at the ventriculotomy, the LVAD inflow cannula was seated, and the remainder of the operation for standard LVAD placement proceeded as per usual.

\section{Statistical Analysis}

Our primary outcomes of interest were postoperative VA and recurrent postoperative VA. Secondary outcomes of interest included mortality and measures of resource use (ie, length of stay, intensive care unit (ICU) stay, and various complications). All group comparisons were unpaired. Bivariate comparisons with either the Pearson $\chi^{2}$ or Fisher exact tests were used for all categoric variables. Analysis of variance was used for all continuous variables. Categoric variable comparisons are expressed as percentages of each group of origin. Continuous variables are reported as mean \pm standard error of the mean. Reported $P$ values are 2-tailed. Data manipulation and analysis were performed with SPSS software (version 19; SPSS Inc, an IBM Company, Chicago, Ill).

\section{RESULTS \\ Comparison of Patient Characteristics and Operative Features}

A total of 50 patients underwent HeartMate II LVAD placement between January 2009 and September 2010. Of these, $54 \%(n=27)$ had the LVAD placed before the index intraoperative cryoablation case in February 2010 (Pre-Index $)$ and $46 \%(n=23)$ underwent LVAD implantation after that index case (Post-Index). Comparing the Pre-Index and Post-Index groups, there were minimal differences in patient demographics, risk factors, preoperative characteristics, or operative features (Table 1). Both groups were predominantly male, had a mean age in the 50 s, had mainly nonischemic cardiomyopathy, and had similar preoperative risk factors. Pre-Index patients had a higher incidence of preoperative inotrope use $(96 \%$ vs $70 \% ; P=.01)$ but no other significant differences existed between groups. Notably, both groups had a high rate of documented preoperative ventricular arrhythmias (Pre-Index, 50.3\%; Post-Index, $69.6 \% ; P=.45)$. As previously mentioned, 14 of 50 total patients had a history of recurrent preoperative VA (multiple documented episodes of VA before LVAD placement) and were selected for subgroup analysis. Seven of these patients were seen before the index case and did not undergo cryoablation (NoCryo); 7 of these patients were seen after development of the protocol and thus underwent intraoperative cryoablation in conjunction with their LVAD implantation (Cryo).

Subgroup comparison of the NoCryo and Cryo groups revealed a similarly homogeneous population. No statistically significant differences were found between groups with 


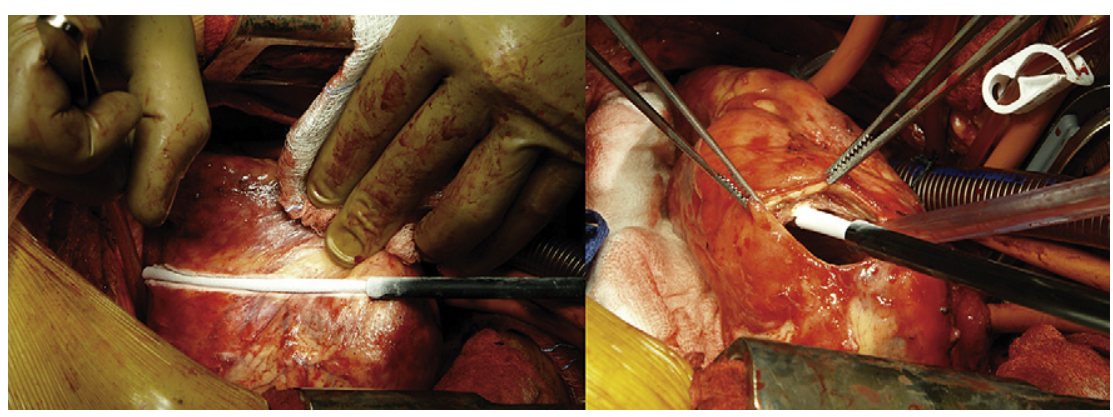

FIGURE 1. Intraoperative epicardial and endocardial cryoablation.

regard to patient characteristics, risk factors, or operative features (Table 2). Again, the earlier NoCryo group trended toward increased preoperative inotrope use $(85.7 \%$ vs $42.9 \% ; P=.09$ ) but this difference did not reach statistical significance. As above, both groups were predominantly male and the majority had nonischemic cardiomyopathy.

\section{Comparison of Outcomes}

An analysis of outcomes of all 50 patients undergoing HeartMate II LVAD implantation during the defined period reveals no statistically significant difference in outcomes between those patients undergoing implantation before the index cryoablation case (Pre-Index) and those patients undergoing implantation after that case (Post-Index) (Table 3). Mortality within 30 days was similarly low, with 1 combined mortality recorded. Mean patient followup was longer in the Pre-Index group (379 vs 148 days; $P<.001)$ inasmuch as this group underwent surgery at an earlier date. Postoperative VAs were common in both groups, with $37 \%$ of Pre-Index patients and $26 \%$ of PostIndex patients having at least 1 episode of documented ventricular tachycardia or fibrillation lasting at least 30 seconds $(P=.41)$. Notably, recurrent postoperative VAs (ie, $>1$ documented episode) were more common in the PreIndex group $(18 \%$ vs $4 \% ; P=.12)$ although this trend did not reach statistical significance. Medical treatment of both atrial and ventricular arrhythmias followed standard clinically accepted protocols and was identical between the Pre-Index and Post-Index groups. We were unable to determine the time between surgery and first VA in all patients but did note that no patient had the first onset of VA outside a 30-day postoperative period. Complications were common in both groups with trends toward increased sepsis $(22 \%$ vs $4 \% ; P=.07)$ and prolonged ventilation $(74 \%$ vs $48 \% ; P=.06)$ in the Pre-Index group. Of Pre-Index patients, $89 \%$ had from at least 1 of 14 preselected STSdefined complications compared with $70 \%$ of the PostIndex group $(P=.09)$. ICU hours, ventilator hours, and postoperative length of stay were similar in both groups.

A subgroup analysis of outcomes in the 14 patients with a history of recurrent preoperative VAs reveals a stark difference in the postoperative course of patients treated with intraoperative cryoablation (Cryo group) compared with those who did not have this procedure (NoCryo group) (Table 4). No deaths occurred within 30 days in either group. Two of the Cryo patients had a single episode of documented of postoperative VA whereas all 7 of the NoCryo patients had at least 1 episode of postoperative VA $(P=.11)$. Of the 2 Cryo patients with a single contained postoperative VA, 1 had an ischemic etiology of heart failure and the other nonischemic. In both cases, a single episode of VA occurred early in the postoperative period and was self-limited. Importantly, none of the Cryo patients had recurrent postoperative VA compared with $4(57 \%)$ of the NoCryo group $(P=.02)$. Of the 4 NoCryo patients with recurrent postoperative VAs, 3 had an identified apical site of the arrhythmogenesis as determined by postoperative EP mapping studies. Although no single complication reached statistical significance, patients undergoing intraoperative cryoablation had fewer complications across the board with 57\% having at least 1 of 14 STS-defined complications compared with $100 \%$ of the NoCryo group $(P=.05)$. Looking at the total number of complications, Cryo patients had a mean of 0.9 complications per patient compared with a mean of 3.0 in the NoCryo group $(P=.05)$. In addition, Cryo patients had a dramatically shorter ICU length of stay (165 vs 441 hours; $P=.01$ ) and postoperative hospital length of stay (26 vs 57 days; $P=.03$ ).

\section{DISCUSSION}

In this study, we have described a novel technique designed to limit postoperative VA in LVAD recipients and have analyzed the results of our early experience with this technique. We have shown first that intraoperative epicardial and endocardial cryoablation is a safe technique when used as described. In addition, when applied to patients with a history of recurrent preoperative VA, intraoperative cryoablation is effective at limiting the incidence of recurrent postoperative VA and may contribute to improvements in other patient outcomes. Despite these findings, the ideal cohort of patients who may benefit from this procedure is unknown. As the incidence of LVAD implantation and the duration of support increase, effective limitation of VAs will be essential for the achievement of optimal 
TABLE 1. Preoperative and operative variables for patients undergoing LVAD implantation before or after the index intraoperative cryoablation procedure

\begin{tabular}{|c|c|c|c|}
\hline Variables & $\begin{array}{c}\text { Pre-Index } \\
(\mathbf{n}=27)\end{array}$ & $\begin{array}{c}\text { Post-Index } \\
(\mathbf{n}=\mathbf{2 3})\end{array}$ & $\begin{array}{c}P \\
\text { Value }\end{array}$ \\
\hline \multicolumn{4}{|l|}{ Demographics } \\
\hline Male & $21(77.8 \%)$ & $17(73.9 \%)$ & .75 \\
\hline Patient age (y) & $50.1 \pm 13.6$ & $54.8 \pm 10.9$ & .19 \\
\hline Height $(\mathrm{cm})$ & $173.4 \pm 11.7$ & $174.6 \pm 7.2$ & .67 \\
\hline Weight $(\mathrm{kg})$ & $81.1 \pm 18.6$ & $85.7 \pm 14.1$ & .34 \\
\hline \multicolumn{4}{|l|}{ Risk factors } \\
\hline Peripheral arterial disease & $2(7.4 \%)$ & $2(8.7 \%)$ & .87 \\
\hline Cerebrovascular disease & $3(11.1 \%)$ & $2(8.7 \%)$ & .78 \\
\hline Chronic lung disease & $4(14.8 \%)$ & $3(13.0 \%)$ & .86 \\
\hline Diabetes & $8(29.6 \%)$ & $5(21.7 \%)$ & .53 \\
\hline Family history of CAD & $12(44.4 \%)$ & $7(30.4 \%)$ & .31 \\
\hline Hypertension & $10(37.0 \%)$ & $13(56.5 \%)$ & .17 \\
\hline Renal failure, dialysis & $1(3.7 \%)$ & $0(0.0 \%)$ & .35 \\
\hline Current or recent smoker & $2(7.4 \%)$ & $2(8.7 \%)$ & .87 \\
\hline Previous MI & $6(22.2 \%)$ & $9(39.1 \%)$ & .19 \\
\hline STS cardiogenic shock & $20(74.1 \%)$ & $16(69.6 \%)$ & .72 \\
\hline Ischemic HF & $8(29.6 \%)$ & $8(34.8 \%)$ & .70 \\
\hline \multicolumn{4}{|l|}{ Medications } \\
\hline Beta-blockers & $13(48.1 \%)$ & $16(69.6 \%)$ & .13 \\
\hline Coumadin & $0(0.0 \%)$ & $1(4.3 \%)$ & .27 \\
\hline Inotropes & $26(96.3 \%)$ & $16(69.6 \%)$ & .01 \\
\hline \multicolumn{4}{|l|}{ Preoperative patient condition } \\
\hline IABP & $6(22.2 \%)$ & $4(17.4 \%)$ & .67 \\
\hline Intubated before VAD & $3(11.1 \%)$ & $1(4.3 \%)$ & .38 \\
\hline Previous AICD & $22(81.5 \%)$ & $21(91.3 \%)$ & .32 \\
\hline Any arrhythmia & $22(81.5 \%)$ & $20(87.0 \%)$ & .60 \\
\hline Atrial fibrillation/flutter & $6(22.2 \%)$ & $8(34.8 \%)$ & .32 \\
\hline $\begin{array}{l}\text { Ventricular tachycardia/ } \\
\text { fibrillation }\end{array}$ & $16(59.3 \%)$ & $16(69.6 \%)$ & .45 \\
\hline Ablation procedure & $3(11.1 \%)$ & $3(13.0 \%)$ & .83 \\
\hline \multicolumn{4}{|l|}{ Intraoperative } \\
\hline Ablation & $0(0.0 \%)$ & $7(30.4 \%)$ & .002 \\
\hline Crossclamp time (min) & $90.8 \pm 34.7$ & $83.3 \pm 21.1$ & .40 \\
\hline Perfusion time (min) & $147.3 \pm 47.3$ & $130.7 \pm 34.0$ & .17 \\
\hline Cryounits & $1.0 \pm 1.0$ & $0.9 \pm 0.8$ & .64 \\
\hline FFP & $6.9 \pm 3.1$ & $7.8 \pm 6.6$ & .52 \\
\hline Platelets & $1.7 \pm 0.8$ & $1.4 \pm 0.7$ & .29 \\
\hline PRBC & $2.9 \pm 2.4$ & $3.0 \pm 4.2$ & .84 \\
\hline
\end{tabular}

Data are shown as $\mathrm{N}(\%)$ or mean \pm standard error of the mean. Boldface indicates values that are statistically significant. $L V A D$, Left ventricular assist device; $C A D$, coronary artery disease; $M I$, myocardial infarction; STS, The Society of Thoracic Surgeons; $H F$, heart failure; $I A B P$, intra-aortic balloon pump; $V A D$, ventricular assist device; $A I C D$, automatic implantable cardiac defibrillator; $F F P$, fresh frozen plasma; $P R B C$, packed red blood cells.

patient outcomes and quality of life. We have presented a promising technique, but further refinement and standardization are necessary to achieve optimal results.

Although it is clear that the most important risk factor for VA in all patients is a reduced ejection fraction, ${ }^{6,7}$ the direct relationship between LVADs and VAs is not entirely understood. Post-LVAD arrhythmias have been attributed to a host of mechanisms including acute left ventricular
TABLE 2. Preoperative and operative variables for patients with a history of recurrent VA undergoing standard LVAD implantations or LVAD implantation with intraoperative cryoablation

\begin{tabular}{|c|c|c|c|}
\hline Variables & $\begin{array}{c}\text { NoCryo } \\
(n=7) \\
\end{array}$ & $\begin{array}{c}\text { Cryo } \\
(n=7)\end{array}$ & $\begin{array}{c}P \\
\text { value }\end{array}$ \\
\hline \multicolumn{4}{|l|}{ Demographics } \\
\hline Male & $5(71.4 \%)$ & $5(71.4 \%)$ & 1.00 \\
\hline Patient age (y) & $48.6 \pm 18.9$ & $47.9 \pm 10.1$ & .93 \\
\hline Height $(\mathrm{cm})$ & $172.2 \pm 8.1$ & $174.1 \pm 5.5$ & .63 \\
\hline Weight $(\mathrm{kg})$ & $77.5 \pm 19.5$ & $87.6 \pm 16.1$ & .33 \\
\hline \multicolumn{4}{|l|}{ Risk factors } \\
\hline Peripheral arterial disease & $0(0.0 \%)$ & $0(0.0 \%)$ & 1.00 \\
\hline Cerebrovascular disease & $1(14.3 \%)$ & $2(28.6 \%)$ & .52 \\
\hline Chronic lung disease & $1(14.3 \%)$ & $0(0.0 \%)$ & .30 \\
\hline Diabetes & $2(28.6 \%)$ & $2(28.6 \%)$ & 1.00 \\
\hline Family history of CAD & $3(42.9 \%)$ & $2(28.6 \%)$ & .58 \\
\hline Hypertension & $0(0.0 \%)$ & $0(0.0 \%)$ & 1.00 \\
\hline Renal failure, dialysis & $2(28.6 \%)$ & $1(14.3 \%)$ & .52 \\
\hline Current or recent smoker & $0(0.0 \%)$ & $1(14.3 \%)$ & .30 \\
\hline Previous MI & $3(42.9 \%)$ & $2(28.6 \%)$ & .58 \\
\hline STS cardiogenic shock & $4(57.1 \%)$ & $3(42.9 \%)$ & .59 \\
\hline Ischemic HF & $3(42.9 \%)$ & $2(28.6 \%)$ & .58 \\
\hline \multicolumn{4}{|l|}{ Medications } \\
\hline Beta-blockers & $5(71.4 \%)$ & $6(85.7 \%)$ & .52 \\
\hline Coumadin & $0(0.0 \%)$ & $0(0.0 \%)$ & 1.00 \\
\hline Inotropes & $6(85.7 \%)$ & $3(42.9 \%)$ & .09 \\
\hline \multicolumn{4}{|l|}{ Preoperative patient condition } \\
\hline IABP & $2(28.6 \%)$ & $2(28.6 \%)$ & 1.00 \\
\hline Intubated before VAD & $0(0.0 \%)$ & $0(0.0 \%)$ & 1.00 \\
\hline Previous AICD & $6(85.7 \%)$ & $6(85.7 \%)$ & 1.00 \\
\hline Any arrhythmia & $7(100.0 \%)$ & $7(100.0 \%)$ & 1.00 \\
\hline Atrial fibrillation/flutter & $0(0.0 \%)$ & $2(28.6 \%)$ & .13 \\
\hline $\begin{array}{l}\text { Ventricular tachycardia/ } \\
\text { fibrillation }\end{array}$ & $7(100.0 \%)$ & $7(100.0 \%)$ & 1.00 \\
\hline Ablation procedure & $3(42.9 \%)$ & $3(42.9 \%)$ & 1.00 \\
\hline \multicolumn{4}{|l|}{ Intraoperative } \\
\hline Ablation & $0(0.0 \%)$ & $7(100.0 \%)$ & $<.001$ \\
\hline Crossclamp time (min) & $97.4 \pm 20.2$ & $83.7 \pm 12.9$ & .18 \\
\hline Perfusion time (min) & $163.3 \pm 42.5$ & $150.7 \pm 30.2$ & .54 \\
\hline Cryounits & $1.6 \pm 1.0$ & $1.0 \pm 1.0$ & .30 \\
\hline FFP & $7.4 \pm 2.4$ & $8.3 \pm 4.5$ & .67 \\
\hline Platelets & $1.9 \pm 0.7$ & $1.6 \pm 0.5$ & .40 \\
\hline PRBC & $4.0 \pm 0.8$ & $2.14 \pm 2.7$ & .10 \\
\hline
\end{tabular}

Data are shown as $\mathrm{N}(\%)$ or mean \pm standard error of the mean. Boldface indicates values that are statistically significant. $V A$, Ventricular tachyarrhythmia; $L V A D$, left ventricular assist device; NoCryo, no cryoablation group; Cryo, cryoablation group; $C A D$, coronary artery disease; $M I$, myocardial infarction; STS, The Society of Thoracic Surgeons; $H F$, heart failure; $I A B P$, intra-aortic balloon pump; $V A D$, ventricular assist device; $A I C D$, automatic implantable cardiac defibrillator; $F F P$, fresh frozen plasma; $P R B C$, packed red blood cells.

unloading with pulsatile devices, ${ }^{8}$ altered ventricular repolarization, ${ }^{9}$ mechanoelectrical feedback from the LVAD motor, ${ }^{10}$ alterations in calcium handing gene expression, ${ }^{11}$ and so called "suction events." 12 VAs in all patients are thought to originate from border-zone areas between cardiac scar tissue and normal myocardium where fibrosis alters the effective refractory period in the action potential 
TABLE 3. Postoperative characteristics for patients undergoing LVAD implantation before or after the index intraoperative cryoablation procedure

\begin{tabular}{lccc}
\hline \multicolumn{1}{c}{ Variables } & $\begin{array}{c}\text { Pre-Index } \\
(\mathbf{n}=\mathbf{2 7})\end{array}$ & $\begin{array}{c}\text { Post-Index } \\
(\mathbf{n}=\mathbf{2 3})\end{array}$ & $\begin{array}{c}\boldsymbol{P} \\
\text { value }\end{array}$ \\
\hline Complications & & & \\
Septicemia & $6(22.2 \%)$ & $1(4.3 \%)$ & .07 \\
Stroke & $3(11.1 \%)$ & $1(4.3 \%)$ & .38 \\
Reoperation for tamponade & $6(22.2 \%)$ & $5(21.7 \%)$ & .97 \\
Other cardiac & $3(11.1 \%)$ & $1(4.3 \%)$ & .38 \\
Other noncardiac & $3(11.1 \%)$ & $2(8.7 \%)$ & .78 \\
Atrial fibrillation & $2(7.4 \%)$ & $1(4.3 \%)$ & .65 \\
Gastrointestinal event & $4(36.4 \%)$ & $7(30.4 \%)$ & .18 \\
Multisystem failure & $2(7.4 \%)$ & $0(0.0 \%)$ & .18 \\
Pneumonia & $7(25.9 \%)$ & $4(17.4 \%)$ & .47 \\
Ventilation prolonged & $20(74.1 \%)$ & $11(47.8 \%)$ & .06 \\
Renal failure & $6(22.2 \%)$ & $5(21.7 \%)$ & .97 \\
Renal dialysis required & $2(7.4 \%)$ & $2(8.7 \%)$ & .87 \\
Embolic stroke & $3(11.1 \%)$ & $1(4.3 \%)$ & .38 \\
Pump pocket infection & $0(0.0 \%)$ & $1(4.3 \%)$ & .27 \\
Any complication & $24(88.9 \%)$ & $16(69.6 \%)$ & .09 \\
Total complications & $2.5 \pm 2.1$ & $1.8 \pm 2.4$ & .30 \\
Death before 30 d & $0(0.0 \%)$ & $1(4.3 \%)$ & .27 \\
Postoperative arrhythmias & & & \\
Ventricular tachycardia/ & $10(37.0 \%)$ & $6(26.1 \%)$ & .41 \\
$\quad$ fibrillation & & & \\
Recurrent ventricular & $5(18.5 \%)$ & $1(4.3 \%)$ & .12 \\
$\quad$ tachycardia/fibrillation & & & \\
Ablation shock procedure & $3(11.1 \%)$ & $0(0.0 \%)$ & .10 \\
Hospital stay & & & \\
Readmission to ICU & $7(25.9 \%)$ & $3(13.0 \%)$ & .26 \\
Reintubated during stay & $6(22.2 \%)$ & $4(17.4 \%)$ & .67 \\
Total ICU time (h) & $415.5 \pm 337.5$ & $422.6 \pm 571.3$ & .96 \\
Ventilation (h) & $143.2 \pm 286.2$ & $134.2 \pm 287.3$ & .91 \\
LOS, admission to & $45.4 \pm 31.8$ & $43.3 \pm 38.6$ & .61 \\
$\quad$ discharge & $11.9 \pm 7.1$ & $9.9 \pm 8.5$ & .38 \\
LOS, admission to surgery & $36.6 \pm 31.9$ & $33.4 \pm 37.9$ & .75 \\
LOS, surgery to discharge & $379.4 \pm 136.5$ & $147.7 \pm 76.4$ & $<. \mathbf{0 0 1}$ \\
Length of follow-up & & & \\
\hline
\end{tabular}

Data are shown as $\mathrm{N}(\%)$ or mean \pm standard error of the mean. Boldface indicates values that are statistically significant. $L V A D$, Left ventricular assist device; ICU, intensive care unit; $L O S$, length of stay.

and reentry circuits responsible for VA are generated. ${ }^{13,14}$ Ventricular stretch is known to be arrhythmogenic, ${ }^{15}$ so one may deduce that decompression of the failing ventricle with LVAD placement should decrease VAs. On the other hand, LVAD insertion fails to specifically treat areas of existing ventricular scar, and the LVAD apical cannula necessarily requires creation of new myocardial scar tissue. Regardless of the relative contribution of these conflicting factors, multiple previous investigations report an increased incidence of VAs after LVAD implantation. ${ }^{3,16}$

Careful analysis of these reports reveals several trends. First, most patients who have post-LVAD VAs experience the first episode early in the postoperative period, and 1 episode often predicts future episodes. ${ }^{1,17}$ In our study, no
TABLE 4. Postoperative characteristic for patients with recurrent preoperative VA

\begin{tabular}{|c|c|c|c|}
\hline Variables & $\begin{array}{l}\text { NoCryo } \\
(n=7)\end{array}$ & $\begin{array}{l}\text { Cryo } \\
(\mathrm{n}=7)\end{array}$ & $\begin{array}{c}P \\
\text { value }\end{array}$ \\
\hline \multicolumn{4}{|l|}{ Complications } \\
\hline Septicemia & $1(14.3 \%)$ & $0(0.0 \%)$ & .30 \\
\hline Stroke & $1(14.3 \%)$ & $0(0.0 \%)$ & .30 \\
\hline Reoperation for tamponade & $2(28.6 \%)$ & $1(14.3 \%)$ & .52 \\
\hline Other cardiac & $1(14.3 \%)$ & $0(0.0 \%)$ & .30 \\
\hline Other noncardiac & $2(28.6 \%)$ & $0(0.0 \%)$ & .13 \\
\hline Atrial fibrillation & $0(0.0 \%)$ & $1(14.3 \%)$ & .30 \\
\hline Gastrointestinal event & $1(14.3 \%)$ & $1(14.3 \%)$ & 1.00 \\
\hline Multisystem failure & $1(14.3 \%)$ & $0(0.0 \%)$ & .30 \\
\hline Pneumonia & $2(28.6 \%)$ & $1(14.3 \%)$ & .52 \\
\hline Ventilation prolonged & $6(85.7 \%)$ & $3(42.9 \%)$ & .09 \\
\hline Renal failure & $2(28.6 \%)$ & $0(0.0 \%)$ & .13 \\
\hline Renal dialysis required & $1(14.3 \%)$ & $0(0.0 \%)$ & .30 \\
\hline Embolic stroke & $1(14.3 \%)$ & $0(0.0 \%)$ & .30 \\
\hline Pump pocket infection & $0(0.0 \%)$ & $0(0.0 \%)$ & 1.00 \\
\hline Any complication & $7(100.0 \%)$ & $4(57.1 \%)$ & .05 \\
\hline Total complications & $3.0 \pm 2.4$ & $0.9 \pm 0.9$ & .05 \\
\hline Death before $30 \mathrm{~d}$ & $0(0.0 \%)$ & $0(0.0 \%)$ & 1.00 \\
\hline \multicolumn{4}{|l|}{ Postoperative arrhythmias } \\
\hline $\begin{array}{l}\text { Ventricular tachycardia/ } \\
\text { fibrillation }\end{array}$ & $7(100.0 \%)$ & $2(25.6 \%)$ & .11 \\
\hline $\begin{array}{l}\text { Recurrent ventricular } \\
\text { tachycardia/fibrillation }\end{array}$ & $4(57.1 \%)$ & $0(0.0 \%)$ & .02 \\
\hline Ablation shock procedure & $2(28.6 \%)$ & $0(0.0 \%)$ & .13 \\
\hline \multicolumn{4}{|l|}{ Hospital stay } \\
\hline Readmission to ICU & $3(42.9 \%)$ & $0(0.0 \%)$ & .05 \\
\hline Reintubated during stay & $3(42.9 \%)$ & $0(0.0 \%)$ & .05 \\
\hline Total ICU time (h) & $441.5 \pm 318.5$ & $165.5 \pm 110.0$ & .01 \\
\hline Ventilation (h) & $209.1 \pm 388.9$ & $31.3 \pm 30.4$ & .25 \\
\hline $\begin{array}{l}\text { LOS, admission to } \\
\text { discharge }\end{array}$ & $71.0 \pm 50.3$ & $31.0 \pm 16.7$ & .07 \\
\hline LOS, admission to surgery & $14.14 \pm 8.8$ & $9.0 \pm 12.9$ & .40 \\
\hline LOS, surgery to discharge & $57.0 \pm 31.0$ & $26.0 \pm 19.0$ & .03 \\
\hline Length of follow-up & $302.9 \pm 142.1$ & $144.9 \pm 76.6$ & .02 \\
\hline
\end{tabular}

Data are shown as $\mathrm{N}(\%)$ or mean \pm standard error of the mean. Boldface indicates values that are statistically significant. $V A$, Ventricular tachyarrhythmia; NoCryo, no cryoablation group; $C r y o$, cryoablation group; $I C U$, intensive care unit; $L O S$, length of stay.

patient had the first episode of VA outside a 30-day postoperative period and $38 \%(6 / 16)$ of those with 1 documented VA had subsequent recurrent episodes. Second, LVAD recipients with preoperative VAs are more likely to have postoperative VAs. ${ }^{17}$ Of the 50 patients studied, 32 had preoperative VA and $41 \%(n=13)$ of these patients had at least 1 episode of postoperative VA. On the other hand, of the 18 patients without preoperative VA, only $17 \%(\mathrm{n}=3)$ had postoperative VA. Third, the high incidence of VAs after LVAD is cause for concern inasmuch as mortality is increased among patients with VAs. ${ }^{16} \mathrm{Al}-$ though the presence of an LVAD mitigates the profound hemodynamic collapse typically seen in unsupported patients, a decrease in LVAD flow output has been demonstrated and 
crude mortality as high as $54 \%$ has been reported for those patients experiencing VAs within 1 week postoperatively. ${ }^{1}$ Bedi and colleagues ${ }^{1}$ reported an overall mortality of $33 \%$ in recipients of pulsatile LVADs experiencing postoperative VAs compared with $18 \%$ when no VA was present $(P<.001)$. Our study failed to show a mortality difference associated with postoperative VAs but nevertheless confirms that a targeted treatment strategy for arrhythmia prevention after LVAD is needed.

Performance of intraoperative cryoablation through the LVAD ventriculotomy has not been reported by other groups, but intraoperative epicardial and endocardial cryoablation during cardiac surgery is by no means a new technique. ${ }^{18}$ In 1994, Dor and colleagues ${ }^{19}$ reported that cryoablation in combination with surgical ventricular reconstruction (SVR) with myocardial scar resection reduced spontaneous and inducible arrhythmias in patients with ischemic VAs. A total of 106 patients were found to have inducible (57) or spontaneous (49) ventricular tachycardia preoperatively and $67 \mathrm{pa}-$ tients underwent non-EP-guided cryoablation at the time of SVR. Postoperatively, ventricular tachycardia was no longer inducible in $92 \%$ of patients and only 2 patients had spontaneous ventricular tachycardia. When following the Dor technique for SVR, intraoperative cryoablation is performed by visual inspection only when the patient has spontaneous or inducible VA preoperatively. ${ }^{18,20-22}$ The goal of SVR is to achieve complete coronary revascularization, reduce left ventricular volume, and restore left ventricular shape to relieve ischemia and reduce wall tension. When combining these principles with myocardial scar resection and visually directed epicardial and endocardial cryoablation, Dor and associates $^{19}$ and subsequent groups ${ }^{23,24}$ have achieved durable arrhythmia-free survival after SVR.

LVAD placement targets a similar patient population to SVR, and although our described technique did not incorporate scar resection, we contend that the LVAD-mediated ventricular decompression along with directed cryoablation of ventricular scar and surrounding tissue achieves a similar result. Notably in the LVAD population, postoperative device support allows for more aggressive use of cryoablation without concerns for reduction in ventricular function. With increased experience using this technique, we have gained comfort performing cryoablation on large sections of ventricle. In fact, in those patients in whom a complete EP mapping study is not feasible and electrocardiographic capture of the VA is difficult, we have ablated almost the entire epicardial and endocardial surfaces of the left ventricle with excellent results. Therefore, although our methods differ from the Dor technique, it should not be surprising that the combination of ventricular decompression and effective cryoablation was similarly effective at reducing postoperative VAs when applied to the LVAD patient population.

Cryoablation during LVAD implantation is a promising technique but optimal patient selection and preoperative targeting require further definition and refinement. In our small series, intraoperative epicardial and endocardial cryoablation have significantly reduced the postoperative arrhythmia burden and resulted in improved patient outcomes. At the very least, our presented results offer a starting place toward the goal of eliminating VAs after LVAD placement. Going forward, we recommend intraoperative cryoablation in all patients with a history of recurrent VA. In the remainder of patients, EP-programmed electrical stimulation may be performed and if spontaneous or inducible ventricular tachycardia is present, cryoablation should be considered at the time of LVAD implantation.

\section{Limitations}

Our study has several limitations. First, the study was retrospective with a limited follow-up time. All patients who had postoperative VAs did so within 30 days of surgery, but longer follow-up is needed to analyze the durability of cryoablation for long-term limitation of postoperative VAs. Additionally, groups were separated by chronologic series, and a component of the cryoablation treatment effect could possibly be attributed to improvements in intraoperative and postoperative care associated with increased experience. We do not believe this is the case inasmuch as Pre-Index and Post-Index patients had similar ICU and hospital lengths of stay despite identical chronologic division to the NoCryo and Cryo groups. Additionally, although we acknowledge that there is no direct link between the presence of recurrent postoperative VA and the cohort of complications and length of stay data analyzed, previous studies have demonstrated both decreased LVAD flows and increased mortality in patients who have postoperative VAs. It should be expected that LVAD recipients with recurrent postoperative VAs will require additional ICU and hospital lengths of stay and may have additional complications related to prolonged convalescence, low flow states, or other factors. Nevertheless, correlation is not causation and we cannot determine the exact role VAs played in the observed increases in length of stay and complications of the NoCryo group.

A further limitation is that the very small sample size of relatively homogeneous patients limits the generalizability of our approach. Ablation was performed only on LVAD recipients with recurrent preoperative VAs. Many LVAD recipients have no preoperative history but do suffer from postoperative VAs, and we are unable to determine whether these patients stand to benefit from intraoperative ablation. Finally, all patients underwent LVAD implantation with a single device (HeartMate II) and we are unable to determine whether our technique would have equal benefit when used with other devices.

\section{CONCLUSIONS}

VAs are common after LVAD placement and their presence contributes to morbidity and mortality after this 
procedure. Postoperative VAs must be limited to realize optimal results after LVAD placement. We have shown that intraoperative epicardial and endocardial cryoablation, when performed during LVAD implantation, reduces the incidence of clinically significant postoperative VAs in a small series of high-risk patients. Optimal application of this technique will require further refinement with focused analysis designed to answer the questions of whom to treat and where to ablate. Widespread adoption of this technique should be feasible both in the United States and worldwide inasmuch as it is safe, easy, and adds minimal time and cost to the standard LVAD implantation procedure. Our promising initial experience with intraoperative cryoablation argues for further application of this novel technique combined with systematic prospective analysis to refine optimal patient selection and application methods.

\section{References}

1. Bedi M, Kormos R, Winowich S, McNamara DM, Mathier MA, Murali S. Ventricular arrhythmias during left ventricular assist device support. Am J Cardiol. 2007;99:1151-3.

2. Refaat M, Chemaly E, Lebeche D, Gwathmey JK, Hajjar RJ. Ventricular arrhythmias after left ventricular assist device implantation. Pacing Clin Electrophysiol. 2008;31:1246-52.

3. Andersen M, Videbaek R, Boesgaard S, Sander K, Hansen PB, Gustafsson F. Incidence of ventricular arrhythmias in patients on long-term support with a continuous-flow assist device (HeartMate II). J Heart Lung Transplant. 2009;28:733-5

4. Oz MD, Rose EA, Slater J, Kuiper JJ, Cantanese KA, Levin HR. Malignant ventricular arrhythmias are well tolerated in patients receiving long-term ventricular assist devices. J Am Coll Cardiol. 1994;24:1688-91.

5. Emaminia A, Nagji AS, Ailawadi G, Bergin JD, Kern JA. Concomitant left ventricular assist device placement and cryoablation for treatment of ventricular tachyarrhythmias associated with heart failure. Ann Thorac Surg. 2011; 92:334-6.

6. Myerburg RJ, Interian A Jr, Mitrani RM, Kessler KM, Castellanos A. Frequency of sudden cardiac death and profiles of risk. Am J Cardiol. 1997;80:10F-9F.

7. Singh BN. Significance and control of cardiac arrhythmias in patients with congestive cardiac failure. Heart Fail Rev. 2002;7:285-300.

8. Harding JD, Piacentino V 3rd, Rothman S, Chambers S, Jessup M, Margulies KB. Prolonged repolarization after ventricular assist device support is associated with arrhythmias in humans with congestive heart failure. J Card Fail. 2005;11:227-32.
9. Grzywacz FW, Piacentino V 3rd, Marble J, Bozorgnia B, Gaughan JP, Rothman SA, et al. Effect of acute unloading via head-up tilt on QTc prolongation in patients with ischemic or non-ischemic cardiomyopathy. Am J Cardiol. 2006;97:412-5.

10. Harding JD, Piacentino V 3rd, Gaughan JP, Houser SR, Margulies KB. Electrophysiologica alterations after mechanical circulatory support in patients with advanced cardiac failure. Circulation. 2001;104:1241-7.

11. Rodriguez-Way A, Burkhoff D, Geesaman BJ, Golden S, Xu J, Pollman MJ, et al Sarcomeric genes involved in reverse remodeling of the heart during left ventricular assist device support. J Heart Lung Transplant. 2005;24:73-80.

12. Vollkron M, Voitl P, Ta J, Wieselthaler G, Schima H. Suction events during left ventricular support and ventricular arrhythmias. J Heart Lung Transplant. 2007; 26:819-25.

13. Stevenson WG, Kyoko S. Catheter ablation for ventricular tachycardia. Circula tion. 2007;115:2750-60.

14. Doenst T, Faerber G, Grandina S, Kuntze T, Menicanti L, Border MA, et al. Surgical therapy of ventricular arrhythmias. Herzchr Elektrophys. 2007;18:62-7.

15. Koilpillai C, Quinones MA, Greenberg B, Limacher MC, Shindler D, Pratt CM, et al. Relation of ventricular size and function to heart failure status and ventricular dysrhythmia in patients with severe left ventricular dysfunction. Am J Cardiol. 1996;77:606-11.

16. Ziv O, Dizon J, Thosani A, Naka Y, Magnano AR, Garan H. Effects of left ventricular assist device therapy on ventricular arrhythmias. J Am Coll Cardiol. 2005;45:1428-34.

17. Oswald H, Klein G, Struber M, Gardiwal A. Implantable defibrillator with left ventricular assist device compatibility. Interact Cardiovasc Thorac Surg. 2009; 8:579-80.

18. Williams JM, Ungerleider RM, Lofland GK, Cox JL. Left atrial isolation: new technique for the treatment of supraventricular arrhythmias. J Thorac Cardiovasc Surg. 1980;80:373-80.

19. Dor V, Sabatier M, Montiglio F, Rossi P, Toso A, Di Donato M. Results of nonguided subtotal endocardiectomy associated with left ventricular reconstruction in patients with ischemic ventricular arrhythmias. J Thorac Cardiovasc Surg. 1994;107:1301-7.

20. Mikleborough LL, Merchant N, Ivanov J, Rao V, Carson S. Left ventricular reconstruction: early and late results. J Thorac Cardiovasc Surg. 2004;128:27-37.

21. Frapier JM, Hubaut JJ, Pasquie JL, Chaptal PA. Large encircling cryoablation without mapping for ventricular tachycardia after anterior myocardial infarction: long-term outcome. J Thorac Cardiovasc Surg. 1998;116:578-83.

22. Thakur RK, Guiraudon GM, Klein GJ, Yee R, Guiraudon CM. Intraoperative mapping is not necessary for VT surgery. Pacing Clin Electrophysiol. 1994;17 2156-62.

23. Sartipy U, Albåge A, Lindblom D. The Dor procedure for left ventricular reconstruction. Ten-year clinical experience. Eur J Cardiothorac Surg. 2005;27: 1005-10.

24. Di Donato M, Sabatier M, Dor V, the RESTORE group. Surgical ventricular restoration in patients with post-infarction coronary artery disease: effectiveness on spontaneous and inducible ventricular tachycardia. Semin Thorac Cardiovasc Surg. 2001;13:480-5. 